\title{
The Price Knowledge Paradox: Why Consumers Have Lower Confidence in, but Better Recall of Unfamiliar Prices
}

\author{
Charlotte Gaston-Breton • Priya Raghubir
}

Published online: 6 June 2014

(C) Springer Science+Business Media New York 2014

\begin{abstract}
This paper introduces the price knowledge paradox: an effect where consumers have lower confidence in their price memory for unfamiliar (versus familiar) prices, but, in fact, have better recall of unfamiliar (versus familiar) prices. We propose that this effect is due to unfamiliar price formats being processed more intentionally, leading to their being better encoded, and accordingly, more accurately retrieved from memory. Familiar price formats, on the other hand, are processed less intentionally, leading to consumers being over confident in their memory for familiar prices. Results from a field experiment with French shoppers $(n=683)$ conducted 6 months prior to the introduction of the Euro, demonstrates that consumers exposed to prices in Euros are almost twice as likely to recall the exact price of the product as compared to those exposed to prices in French Francs, although only $69 \%$ of those seeing Euro prices (versus $85 \%$ in FFs) said they could recall the price - the price knowledge paradox. Importantly, these effects carry through to intentions to purchase. The theoretical contributions of the manner in which consumers' process familiar versus unfamiliar price information has implications for international pricing managers and public authorities facing monetary changes across and within countries.
\end{abstract}

Keywords Price memory · Consumer knowledge $\cdot$ Price information processing $\cdot$ Monetary changeover $\cdot$ Retail price presentation format

C. Gaston-Breton $(\square)$

Madrid Campus, ESCP Europe, C/. Arroyofresno, 1, 28035 Madrid, Spain

e-mail: cgaston-breton@escpeurope.eu

\section{P. Raghubir}

Stern School of Business, New York University, 40 West 4th Street, Suite 809 Tisch, New York, NY 10012-1126, USA

e-mail: raghubir@stern.nyu.edu

\section{Introduction}

If you are a retailer who needs to decide whether to communicate the price of your product in a local currency or in different currencies, what could and should guide you? Duty free stores, airline catalogs, and retailers in tourist locations over the world face this question. Is the answer contingent on whether the store has a price advantage or not? There is limited academic work that can help them make a decision. This article aims at plugging that hole using the monetary changeover to the Euro as its context. As such, the results also speak to public policy and consumer welfare groups that are dealing with the relatively uncommon situation of a monetary changeover.

Despite decades of research on pricing, relatively little is known about how consumers' beliefs about their memory for prices reflects how they actually process price information and retrieve it from memory. Price knowledge studies have traditionally focused on price memory estimates and show that a very high percentage of consumers do not accurately recall prices even immediately after purchasing a product $[7,11]$. This paper examines whether the familiarity of the price format moderates the poor recall of prices, and how well consumers are calibrated in terms of their price knowledge: Do they know what they know?

We introduce a counterintuitive effect- the price knowledge paradox. The price knowledge paradox captures the phenomenon that consumers have lower confidence in their price memory for unfamiliar (versus familiar) prices, but, in fact, have better recall of unfamiliar (versus familiar) prices. We propose that this effect is due to the greater intentional processing of an unfamiliar price format leading to its being better encoded, and accordingly, more likely to be accurately retrieved from memory. Familiar price formats, on the other hand, are processed less intentionally, leading to consumers being overconfident in their memory for familiar prices. 
Accordingly, while price accuracy does not affect intentions to purchase when prices are in familiar formats, when they are in unfamiliar formats, intentions are higher the more prices are underestimated.

Together, these results lead to the counterintuitive managerial recommendation that if a store has a price advantage over another one, it should not communicate its prices in a currency that is familiar to its target consumer (e.g., US\$ to a US tourist), but rather only use a local currency that is unfamiliar, as that currency will be more intentionally processed, be better recalled, and, as it is lower than competition, will translate into higher purchase intentions.

The need to examine the effect of price presentation formats is important due to the variance in such formats [10], as well as changes in the expression of monetary forms both across countries (e.g., foreign currency) and within countries (e.g., devaluations, Euro introduction) which lead to price formats that are differentially familiar and complex to consumers. A currency change is a critical situation for the growing number of consumers who travel (i.e., as much as 1.6 billion of internationals arrivals are expected by 2020 according to the United Nations World Tourism Organization) with prior research showing that the type of foreign currency can affect tourists willingness to purchase and the prices they are willing to pay [18]. As retailers often have choices in terms of which currencies to use to communicate the prices of products they sell, the issue of how consumers react to different price formats is a critical one for them.

We use the context of the Euro monetary changeover to examine this question. Over 300 million people had to adapt to the new Euro currency when it was introduced in January 2002 in 12 countries (including France, Germany, Spain, Italy, and Portugal). The issue of the impact of the Euro introduction, far from being of mere historical interest, remains a current topic as countries have continually been added to the Eurozone since 2002 (e.g., Slovenia in 2007, Cyprus and Malta in 2008, and Slovakia in 2009). In 2011, there is continuing conversation in another $11 \mathrm{EU}$ members to join the Eurozone (e.g., UK, Denmark, Sweden, Estonia, Bulgaria, Poland, Romania), with EU candidates (e.g., Turkey and Croatia) also interested in adopting the Euro. In 2013, there were some concerns that some of the original Euro countries (e.g., Greece), may revert to their original local currency. What are the implications of a monetary changeover for long-term and short-term price knowledge and how will it affect consumers' purchase intentions? More importantly, what are the lessons from a monetary changeover that retailers, like duty free shops, can use to communicate their prices.

Studies examining the effect of the currency changes on long-term price knowledge have found inconsistent results in terms of whether price knowledge has improved or worsened [1, 2, 19]. Aalto-Setälä and Raijas [1] asked consumers to estimate prices before and after the Euro introduction in Finland and found that consumers were more inaccurate after the Euro introduction. On the other hand, Schneider and Kelemci Schneider [19] who examined the effect of the devaluation of the Turkish lira found no deterioration, but, in fact, a slight improvement of price knowledge. Consumers were more accurate at recalling prices in the new currency; a result they explained due to arithmetic ease of conversion. Note that the devaluation on the Turkish Lira only divided the old Lira by 1,000 , so the new currency was rescaled, but not necessarily unfamiliar - a factor that may potentially reconcile these contradictory findings for long-term price memory. Neither of these studies examined the effect of price knowledge on purchase intentions. This paper examines short-term price knowledge due to the potential impact it can have on purchase intentions.

The results for studies examining short-term memory have shown higher levels of accuracy as would be expected given that recall should be increasingly inaccurate as the amount of time that elapses between the time when the unfamiliar prices are encoded and retrieved from memory increases [2]. However, prior research on short-term price knowledge has shown that most consumers do not know the exact prices of products at the point of purchase. Dickson and Sawyer [7] originally documented that a mere 30 seconds after selecting a product, only one in two American shoppers was able to accurately recall prices. In an extended replication of this study, Le Boutillier, Shore Le Boutillier, and Neslin [11] found that accurate levels of recall were only as high as $61.3 \%$ in the soda and coffee categories. Much lower numbers were reported by Vanhuele and Drèze [21] who showed that, in France, when shoppers were intercepted after a simulated or real buying situation, accurate price recall scores were $2.1 \%$ (for longer term memory) to $10 \%$ (for immediate price memory after purchasing yogurt or mineral water). Recognition scores topped out at $42.2 \%$ - an overall low level of accuracy.

In this paper, we examine the moderating effect of the familiarity of the price format on this poor price recall. We propose that there are two aspects of consumer price knowledge: confidence and accuracy, and while the familiarity of a price format increases confidence, it decreases accuracy. If consumers experience a potential disconnect between their beliefs in, versus actual memory of, familiar versus unfamiliar price information, they do not know what they know. This implies that shoppers are likely to be less confident, but more accurate about their price memory for Euros as compared to French Francs, whereas with French Francs (FFs) they should show the classic overconfidence effect [7].

Results from a field experiment with French shoppers $(n=$ 683 ) conducted 6 months prior to the introduction of the Euro, demonstrated that consumers exposed to prices in Euros, an unfamiliar price format, were almost twice as likely to recall the exact price of the product as compared to those exposed to 
prices in French Francs (a familiar price format). This is despite only $69 \%$ of those seeing Euro prices (versus $85 \%$ in FFs) reporting they could recall the price. This is the price knowledge paradox that captures that consumers do not know what they know. They think they know more than they do when prices are in familiar FF formats and they think they know less than they do when prices are in unfamiliar Euro formats. Importantly, these effects carry through to intentions to purchase: While consumers are less likely to have erroneous memory with an unfamiliar currency $(€ s)$, when they do, the direction of their memory errors has a significant impact on purchase intention.

To summarize, in this paper, we:

1. Attempt to bridge the literature on the effect of the Euro changeover (that affected the familiarity of price formats) with the literature on short-term price knowledge to assess whether the introduction of the Euro worsened or improved short-term memory of prices.

2. Examine whether the effects of the Euro changeover are in the same or in different directions for two different measures of price knowledge: price recall and recognition that tap different ways in which prices are processed [15] to understand differences in how familiar and unfamiliar prices are processed.

3. Explore whether consumers are aware of their price knowledge. We argue that consumers believe they know more than they do for familiar price formats; consistent with Dickson and Sawyer's [7] results, but for unfamiliar price formats consumers know more than they believe they do.

4. Assess the consequences of price presentation and price memory on purchase intentions.

This paper makes the following contributions: (a) demonstrates the price knowledge paradox whereby consumers believe they know less but are more accurate in their price recall of unfamiliar Euro (versus familiar FF) prices, (b) demonstrates that prices in Euros are better recalled but prices in FFs are better recognized conditional on not being accurately recalled - that is, have a recognition advantage, (c) shows that unfamiliar price formats attenuate the high levels of inaccuracy of price recall noted in price knowledge research, and (d) shows the carry over effect of accuracy of price memory for unfamiliar prices on intentions.

Theoretically, this research contributes to our understanding of price information processing and memory processes. Managerially, it has implications for price presentation formats for retailers and manufacturers that target foreign consumers in duty free shops or in tourist places over the world. Methodologically, we show how differences in measures (confidence, recall and recognition accuracy, recognition advantage, and the direction of errors) can together be used to understand how prices are processed, intentionally versus incidentally, and whether consumers are aware of their price knowledge. After a brief literature review and summary of our hypotheses, we describe the field experiment conducted to test the theory. We follow up with a discussion of our theoretical, managerial, and methodological implications.

\section{Literature Review and Hypotheses}

\subsection{Confidence in Price Knowledge}

Consumers have a higher degree of uncertainty in estimating unfamiliar information [3]. The expression of prices in a new monetary unit affects both visual and cognitive information conveyed by prices. As prices memorized in the former currency become obsolete in the assessment of prices in the new currency, consumers are more uncertain about prices [12]. Depending on the exchange rate between the new and the old currency units, the nominal value of prices displayed either increases or decreases and, therefore, the degree of uncertainty about the real value of products may vary. However, both in the case of an easy monetary change as the currency devaluation in Turkey [4] or for more complex arithmetic conversion as for the Euro introduction [16], prior research shows that buyers are prone to "money illusion" effects (cf. [20]) at the initial time of introduction of the new currency standard. The shift from the French Francs to the Euros leads to a complex arithmetic conversion $(€ 1=$ FF6.657) so that consumer uncertainty about their price knowledge should be higher with Euros compared to FFs. Therefore, we propose that:

H1: Consumers are more confident of their price knowledge for familiar versus unfamiliar price formats (FFs vs. $€$ s).

\subsection{Recall and Recognition Accuracy}

The retrieval of price information stored in memory is frequently measured using either or both of price recall and recognition tests [21]. Recall accuracy can be defined either in terms of exact recall of prices, or in terms of the percentage difference between the recalled price and the correct price. Consumers' performance in recognition tests is commonly measured through the ability to recognize the correct price among a limited list of prices.

There are three reasons why familiarity of price formats should affect recall and recognition accuracy: level of attention, type of encoding, and presence of internal reference prices. Firstly, unfamiliar price formats should attract greater attention. This is because new or unusual price information is more likely to stand out [22]. As Euro price formats were less 
familiar than French Francs at the time of their introduction, they should have attracted greater attention, leading to improved price recall.

Secondly, Euro prices should be better encoded than French francs. This is because prices in Euros are a fraction of the prices in FF ( $€ 1=F F 6.657)$, so when the price is in Euros it is lower in nominal terms, making the task of storing its exact value in memory easier. Further, prices are stored in visual memory with price figures retained in their exact form with an accuracy that decreases from left to right. These magnitude representations are arrayed in an analog format along a left-to-right mental number line [17] and reflect either the exact or the approximate value of the number [6]. Thus, in many cases lower nominal Euro prices are easier to encode, and should be better recalled than prices in FF (e.g., €1= FF6.66), though this would not always be the case (e.g., $€ 1.20=$ FF8.00).

Thirdly, unfamiliar prices do not have well established reference prices unlike familiar prices. The presence of reference prices, external (ERP, [9]), and internal (IRP), individually and collectively affect price evaluations [14]. In order to categorize new price information (in $€$ ), consumers should use ERPs that are more accessible and appropriate than IRPs that are stored in memory with the old currency unit (in FF). By comparing observed prices with other available price references in the purchasing environment, consumers should pay more attention to price digits and, in turn, be more likely to store the numeric form of those prices in memory. This should translate into better price recall in Euros than if prices were presented in FFs. Thus, the absence of easily available IRPs for Euros is a third reason why consumers are likely to better recall prices presented in Euros as compared to FFs.

To summarize, due to higher attention, better encoding and numerical storage of prices in memory, and lack of IRPs for unfamiliar versus familiar formats, we propose:

$\mathrm{H} 2$ : Shoppers memory for prices expressed in an unfamiliar monetary unit (€s) is more accurate than the same prices expressed in a familiar monetary unit (FFs).

\subsection{Recognition Advantage}

There are two measures of price memory: recall and recognition. Recognition is easier than recall, leading to greater recognition accuracy than recall accuracy. We define "recognition advantage" as the extent to which recognition accuracy is greater than recall accuracy, and propose that it elucidates the manner in which information has been processed. This is because, whereas both recall and recognition tap the accuracy of memory, they do so in different ways. Retention of price information is about storing price information in short-term or working memory. Working memory can be activated either in an implicit fashion, when there's no conscious knowledge of price information or in an explicit manner, when price information has been consciously processed and then stored in memory [15].

Consumers have been modeled as storing price information in working memory in both numeric and evaluative forms according to their purchasing experience and the importance of price information for the purchase decision. Mazumdar and Monroe [13] suggest that shoppers are more likely to store price information in its exact numeric form (e.g., "The price of this bottle of wine is $€ 7.56$.") or its approximate numeric form (e.g., "The price of this bottle of wine is around $7 € s$. .") if the price information is acquired intentionally. Further, explicit price knowledge is usually operationalized by asking the exact price of a certain product, whereas implicit knowledge can be assessed using a semantic differential scale such as "more-less expensive" or "value for money" [5].

We argued in $\mathrm{H} 2$, that in the context of unfamiliar prices $(€ s)$, consumers are more likely to consciously and intentionally process price information than in the context of familiar prices (FFs). Thus, they should be more accurate in estimating the exact numeric form of Euro prices as compared to FF prices, leading to superior recall and recognition of Euro prices (versus FF prices).

As reviewed above, the responses to price recall tasks are closely linked to the intentional extraction of information stored in memory. However, answers to price recognition tests are based on familiarity that does not always correspond to a conscious information retrieval task. Recognition tasks are performed better than recall tasks as they involve easier retrieval activity with less intentional processing of prices - that is they have an advantage over recall. If, as argued, familiar price formats are processed less intentionally than unfamiliar ones, then when prices are expressed in a familiar format, price recognition should be easier than price recall (the recognition advantage). However, for unfamiliar formats where prices have been processed more intentionally to begin with and recall is high, recognition may not provide as much of an advantage over recall. Thus, we propose that there will be a higher recognition advantage for the familiar input that has been less intentionally processed as compared to the input that has been more intentionally processed, or:

H3: Familiarity of price format interacts with price memory measures, such that there will be a greater recognition advantage for familiar price formats (FFs), as compared to unfamiliar price formats $(€ s)$.

\subsection{Consequences of Price Processing on Purchase Intentions}

$\mathrm{H} 1$ to $\mathrm{H} 3$ are in the domain of price memory: confidence in memory (H1), the accuracy of memory (H2), and the type of 
memory outputs (H3). We now examine the downstream consequences of these memory outputs on purchase intentions. Specifically, we have proposed that unfamiliar currencies are processed more intentionally than familiar currencies leading to more accurate price memory for Euros compared to FFs. We now argue that the more intentionally prices are processed, the higher levels of conscious attention, leading to shoppers' price estimation having a greater impact on purchase intentions (vs. less intentionally processed prices). Thus, consumers paying more attention to unfamiliar prices (Euros), should, in turn, be more influenced by price recall accuracy and type of errors than consumers facing familiar prices (FFs). In particular, shoppers who inaccurately underestimate prices in Euros should have higher purchase intentions than those who overestimate these prices.

H4: Familiarity of price format and direction of recall errors interact, such that

a. For unfamiliar price formats ( $€ \mathrm{~s})$, purchase intentions will be higher for those who underestimate versus those who overestimate prices.

b. For familiar currency formats (FFs), the effect of direction of recall errors will be attenuated.

The experimental field study conducted to test these hypotheses is now described.

\section{Study Methodology}

\subsection{Sample}

Two stores (Carrefour hypermarkets in France) were selected for data collection. The interviews were carried out over a 3week period, 6 months before the introduction of the Euro (Summer 2001). Shoppers were intercepted at the stores' entrances and exits. Because we expected to find different types of shoppers at different times of the day and the week, the interviews were scheduled in such a way that each relevant time slot could be covered (morning, midday, evening, beginning of the week, and end of the week). To qualify for the interview, shoppers needed to pass three filter questions: they needed to be the regular shopper for their family, they needed to do their regular shopping at the Carrefour store, and they needed to have bought the product category: sunflower oil. The selected product category is a typical commodity in the French shopping basket for which price is an important choice attribute. After responding to the three filter questions, respondents were invited to take part in the experiment. The sample had age and gender quotas that were elicited after the filter questions, such that half the respondents would be male, and the other half female; and half the respondents would be born before 1951, and the other half in 1951 or later. A total of 683 interviews were carried out at the stores' entrances. The respondents were assigned at random to one of two experimental conditions: prices in FF or Euro.

The sample characteristics reflected the general population characteristics of France (as per the 2005 French National Institute of Statistics and Economic Studies or INSEE census). The population is composed of $48 \%$ males (sample $=47 \%$ ); with a median age of 40 years ( sample $=41.5$ ); and an average monthly per capita income of FF16K (Sample=FF15K).

\subsection{Design and Procedure}

We used a one way between subjects design manipulating price presentation format: Euro or FF. Shoppers were questioned about a single brand, Carrefour sunflower oil, to keep the task easy. Store checks and panels of prices in the Carrefour database showed that during the period of the study, the normal price level for Carrefour sunflower oil was FF9.42 $(€ 1.44)$.

On agreeing to participate, the participants were handed the experimental materials and were asked to carefully read and answer questions relating to their buying behavior regarding sunflower oil products and the Carrefour brand. These questions included three agree-disagree questions elicited on a seven-point scale ("I frequently buy sunflower oil," "I know the different brands of sunflower oil," and "I believe that national brands of sunflower oil are higher quality than private label brands" $)^{1}$ and the purchase frequency for the brand $(-3=$ Never; $3=$ Always).

After this set of questions, the picture of Carrefour sunflower oil was displayed along with the price depending on which price condition shoppers were assigned to. Shoppers were asked to evaluate the value for money of this product and, then, they indicated their purchase intentions for the brand by responding to their level of agreement with the statement "I will buy the Carrefour brand" using a sevenpoint scale ranging from -3 (Strongly disagree) to +3 (Strongly agree). There were no differences across conditions on these measures.

After completing three questions eliciting demographic information: per capita income, occupation, and number of people in the household, shoppers were invited to voluntarily participate in a surprise price memory task. Of the original 683 who agreed to participate in the survey, 527 (77\%) said they could recall the exact price and $621(91 \%)$ reported they could perform the easier memory task of recognition. Shoppers were first asked whether or not they recalled the price of the brand. If they said they did, they indicated what the price was in an

\footnotetext{
${ }^{1}$ Sentences are English translations from French, the language of administration.
} 
open-ended response format $(n=527)$. Subsequently, irrespective of their beliefs in accurately recalling price, the 683 respondents were asked to recognize the correct price from a list presented. If they said they could, they indicated the recognized price among a list of thirteen plausible prices including prices that were $50 \%$ higher and $50 \%$ lower than the actual price, embedded within which was the actual price of the product $(n=621)$. The likelihood of explicitly recalling and recognizing a price were used as two measures of confidence in price memory to test $\mathrm{H} 1$.

Price memory was operationalized using the likelihood of accurate recall and recognition to test $\mathrm{H} 2$. The open-ended price recall response and the recognition of the actual price within the list of prices were coded as accurate, underestimate, or overestimate. Actual recall and recognition accuracy scores are calculated as a percentage of the total sample $(n=683)$, the subsample who report they could recognize the actual price $(n=621)$, and the smaller subsample that said they could recall the price of the product $(n=527)$. We operationalized recognition advantage as the percentage of shoppers who were able to accurately recognize a price despite not being able to accurately recall it. The percentage of consumers saying they could accurately recall and recognize the price, actual recall and recognition accuracy, and recognition advantage are presented in Table 1.

\subsection{Dependent Measures}

To summarize, confidence was measured as the percentage of respondents stating they could accurately recognize and recall price. Price memory was measured as a function of whether price was accurately recalled and/or recognized. Recognition

Table 1 Price memory for familiar and unfamiliar currencies

\begin{tabular}{|c|c|c|c|c|c|c|}
\hline \multicolumn{3}{|c|}{ Dependent measures } & \multirow{2}{*}{$\frac{\text { Familiar FF }}{345}$} & \multirow{2}{*}{$\begin{array}{l}\text { Unfamiliar } € \\
338\end{array}$} & \multirow{2}{*}{$\begin{array}{c}\text { Total } \\
683\end{array}$} & \multirow[t]{2}{*}{$p<$} \\
\hline 1 & \multicolumn{2}{|c|}{ Total sample } & & & & \\
\hline \multicolumn{7}{|c|}{ H1: confidence in memory is greater for FF vs. $€$ : Evidence that shoppers are unaware that they intentionally process $€$ more than FF } \\
\hline \multirow[t]{2}{*}{2} & \multicolumn{2}{|c|}{ Number reporting that they could recognize the price } & 328 & 293 & \multicolumn{2}{|c|}{621} \\
\hline & $(2) /(1)$ & $\%$ of the full sample & 95.07 & 86.69 & 90.92 & 0.05 \\
\hline 3 & \multicolumn{2}{|c|}{ Number reporting that they could recall the price ${ }^{\mathrm{a}}$} & 294 & 233 & 527 & \\
\hline $3 \mathrm{a}$ & $(3) /(1)$ & $\%$ of the full sample & 85.22 & 68.93 & 77.16 & 0.05 \\
\hline $3 \mathrm{~b}$ & $(3) /(2)$ & $\%$ of those reporting they could recognize price & 89.63 & 79.52 & 84.86 & 0.05 \\
\hline \multicolumn{7}{|c|}{$\mathrm{H} 2$ : recall and recognition accuracy is greater for $€$ vs. FF: Evidence for greater intentional processing of $€$} \\
\hline 4 & \multicolumn{2}{|c|}{ Number accurately recalling price } & 71 & 154 & 225 & \\
\hline $4 \mathrm{a}$ & $(4) /(1)$ & $\%$ of the full sample & 20.58 & 45.56 & 32.94 & 0.05 \\
\hline $4 b$ & $(4) /(2)$ & $\%$ of those reporting they could recognize price & 21.65 & 52.56 & 36.23 & 0.05 \\
\hline $4 \mathrm{c}$ & $(4) /(3)$ & $\%$ of those reporting they could recall the price & 24.15 & 66.09 & 42.69 & 0.05 \\
\hline 5 & \multicolumn{2}{|c|}{ Number accurately recognizing price ${ }^{\mathrm{b}}$} & 180 & 221 & 401 & \\
\hline $5 \mathrm{a}$ & $(5) /(1)$ & $\%$ of the full sample & 52.17 & 65.38 & 58.71 & 0.05 \\
\hline $5 b$ & $(5) /(2)$ & $\%$ of those reporting they could recognize price & 54.88 & 75.43 & 64.57 & 0.05 \\
\hline $5 \mathrm{c}$ & $(5) /(3)$ & $\%$ of those reporting they could recall the price & 61.22 & 94.85 & 76.10 & 0.05 \\
\hline \multicolumn{7}{|c|}{ H3: recognition advantage is greater for FF vs. $€$ : Evidence for greater incidental processing of FF } \\
\hline 6 & \multicolumn{2}{|c|}{ Inaccurate in recall, accurate in recognition } & 103 & 44 & 147 & \\
\hline $6 \mathrm{a}$ & $(6) /(1)$ & $\%$ of the full sample & 29.86 & 13.02 & 21.52 & 0.05 \\
\hline $6 \mathrm{~b}$ & $(6) /(2)$ & $\%$ of those reporting they could recognize price & 31.40 & 15.02 & 23.67 & 0.05 \\
\hline $6 \mathrm{c}$ & $(6) /(3)$ & $\%$ of those reporting they could recall the price & 35.03 & 18.88 & 27.89 & 0.05 \\
\hline 7 & \multicolumn{2}{|c|}{ Inaccurate recall and recognition } & 120 & 35 & 155 & \\
\hline $7 \mathrm{a}$ & $(7) /(1)$ & $\%$ of the full sample & 34.78 & 10.35 & 22.69 & 0.05 \\
\hline $7 \mathrm{~b}$ & $(7) /(2)$ & $\%$ of those reporting they could recognize price & 36.58 & 11.94 & 24.96 & 0.05 \\
\hline $7 \mathrm{c}$ & $(7) /(3)$ & $\%$ of those reporting they could recall the price & 40.82 & 15.02 & 29.41 & 0.05 \\
\hline
\end{tabular}

${ }^{a}$ Row 3 is composed of those who can accurately recall (and therefore accurately recognize) price (Row 4), those who cannot recall, but can accurately recognize price (Row 6), and those who cannot accurately recognize (or recall) price (Row 7)

${ }^{\mathrm{b}}$ Row 5 reporting total accurate recognition, is made up of rows 4 and 6 (accurate recall and recognition, inaccurate recall but accurate recognition) and those who report they could not recall the exact price but accurately recognize the price: $n$ total $=29 ; n \mathrm{FF}=6=180-(103+71)$; $n €=23=221-(44+154)$ 
advantage was measured as the likelihood of correctly recognizing a price, given that it had not been recalled accurately. We also examined the implications of currency formats on intentions to purchase the product.

\section{Results}

Table 1 provides results, by measure, for original (FF) and unfamiliar $(€)$ currencies $(\mathrm{H} 1-\mathrm{H} 3)$. The price knowledge paradox contrasting the confidence in memory (H1) and accuracy of memory (H2) is presented graphically in Fig. 1. Figure 1 also presents the contrast between accuracy of memory (H2) and recognition advantage (H3) that illuminates the intentional versus incidental processing of price as a function of familiarity of price formats.

\subsection{Confidence in Price Memory}

As expected, an overall lower percentage of consumers reported that they could recognize or recall the exact price when it was presented in the unfamiliar Euro currency (293/338 or $86.7 \%$ for the recognition task and $233 / 338$ or $68.9 \%$ for the recall task) versus the familiar FF currency $(328 / 345$ or $95.1 \%$ for the recognition task and $294 / 345$ or $85.2 \%$ for the recall task; $\chi^{2} \mathrm{~s}=14.55$ and 25.68 , respectively, with $p<0.05$; see rows 2 and $3 \mathrm{a}$ of Table 1 ). The results are the same among the subset of those consumers who reported they could perform the recognition task (for $€, 233 / 293$ or $79.5 \%$; for FF, $294 / 328$ or $89.6 \% ; \chi^{2}=12.32, p<0.05$; see row $3 \mathrm{~b}$ of Table 1). Thus, H1 arguing that people would be less confident about their memory for the unfamiliar Euro format (versus the familiar FF format) was supported.

\subsection{Price Memory}

$\mathrm{H} 2$ predicted better recall and recognition for Euro prices as compared to FF prices. Results are presented in rows 4 and 5 of Table 1 . Whereas as many as $66.1 \%(154 / 233)$ of the shoppers who recalled a price recalled it correctly when it was presented in Euros, only $24.1 \%$ (71/294) did so when it was expressed in FFs $\left(\chi^{2}=93.47, p<0.001\right.$, see row $\left.4 \mathrm{c}\right)$. Results are the same if we examine the percentage of consumers who accurately recall a price of all consumers in the condition rather than the subset of those consumers who actually recalled the price (see row $4 \mathrm{a}, 45.6 \%$ or $154 / 338$ vs. $20.6 \%$ or $71 / 345$ for Euro vs. FF, respectively, $\chi^{2}=48.24$, $p<0.001$ ). These findings are also reflected among those saying they could recognize the actual price (see row $4 \mathrm{~b}$, $52.6 \%$ or $154 / 293$ vs. $21.6 \%$ or $71 / 328$ for Euro vs. FF, respectively, $\left.\chi^{2}=64.01, p<0.001\right)$. Thus, despite having lower confidence in their price memory (H1), consumers exposed to prices in Euro are, in fact, over twice as likely to recall the exact price of the product as compared to those exposed to prices in FF. H2 was, therefore, supported for the measure of price recall. We next examine the measure of price recognition.

Consistent with $\mathrm{H} 2$, and reflecting the results of the recall task, in the Euro condition, as many as $75.4 \% \%$ (221/293) of those who report recognizing a price, correctly recognized it, as compared to $54.8 \%(180 / 328)$ who did so in the FF condition $\left(\chi^{2}=28.56, p<0.001\right.$; see row $\left.5 \mathrm{~b}\right)$. Given that a lower percentage of consumers had agreed to participate in

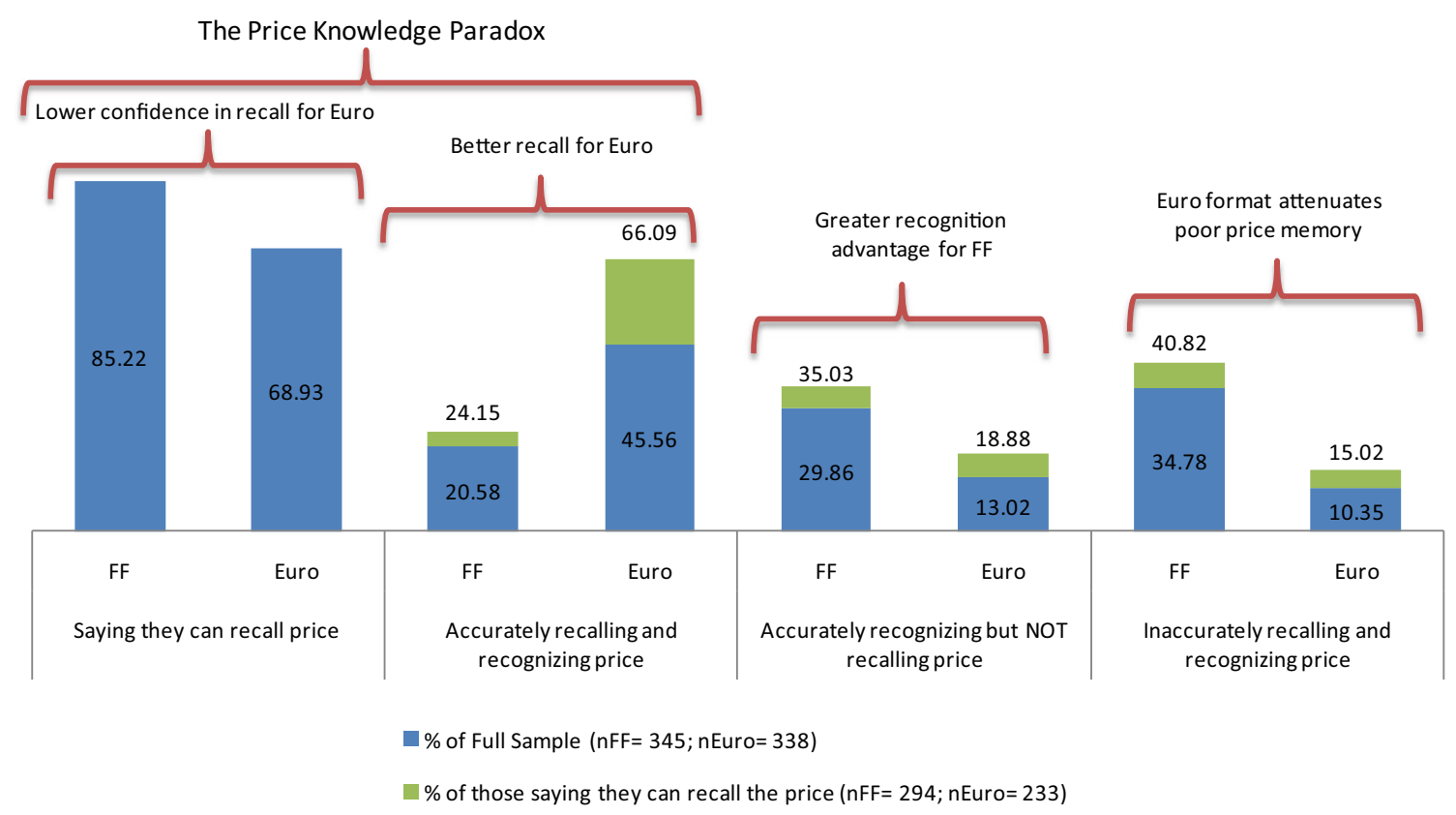

Fig. 1 The price knowledge confidence and accuracy for FFs and Euros 
the recognition task when it was in the unfamiliar currency, we examined the number of consumers who accurately recognized the price as a percentage of all consumers in that condition. Reflecting earlier results, a higher percentage of all shoppers in the Euro (versus FF) condition recognized price accurately ( $65.4 \%$ vs. $52.2 \%$ or $221 / 338$ vs. $180 / 345$ for Euro vs. FF, respectively, $\chi^{2}=12.29, p<0.05$; see row $5 \mathrm{a}$ ). Among those performing the recall task, the corresponding percentages are $94.8 \%(221 / 233)$ for Euro versus $61.2 \%$ for FF $\left(180 / 294, \chi^{2}=28.57, p<0.001\right.$; see row 5 c). Thus, H2 that argued that shoppers would have more accurate memory for prices in an unfamiliar versus familiar currency, despite being more confident of their price memory for familiar currency formats (H1), was supported. This is the price knowledge paradox effect of lower confidence but higher accuracy in price memory for unfamiliar prices.

\subsection{Recognition Advantage}

$\mathrm{H} 3$ argued that when prices are processed intentionally, then recognition performance should reflect recall performance, but when they are processed incidentally then recognition performance should be substantially better than recall performance - the recognition advantage. H3 predicted that the output of a memory process (recall or recognition) would interact with the currency in which prices were provided. To test $\mathrm{H} 3$, we now examine whether the relationship between recall and recognition accuracy is contingent on the currency in which prices were provided. Results are provided in Row 6 of Table 1.

There is a higher recognition advantage for FFs versus Euros. Specifically, 103 shoppers who had been unable to recall an accurate price in FF were able to accurately recognize it $(29.9,31.4$, and $35.0 \%$ of the full sample, those recognizing a price, and those recalling a price, respectively), as compared to 44 shoppers who had seen the price in Euros $(13.0,15.0$, and $18.9 \%$ of the full sample, those recognizing a price, and those recalling a price, respectively, $\chi^{2} s=26.22,23.00$, and $16.86, p<0.05$ for all, see rows $6 \mathrm{a}-6 \mathrm{c}$ ).

Note that recognition accuracy for FF is $55 \%$ (based on those saying they can recognize a price, row $5 \mathrm{~b}$ ) and recall accuracy is $24 \%$ (based on those saying they can recall a price, row $4 \mathrm{c}$ ), with the analogous numbers for Euros being 75 and $66 \%$. Despite the high levels of recognition accuracy for Euros, the recognition advantage results are unlikely to represent a ceiling effect. This is because the recognition advantage for FFs could have been lower than for the Euros. Said differently, while there may be limited scope to increase the recognition accuracy of Euros, there is plenty of scope to reduce the recognition accuracy of FFs. A low recognition advantage would, in fact, be expected if shoppers did not process FF prices even slightly intentionally. In this scenario, FFs would have an equal or lower recognition advantage over the Euro (contrary to H3). However, if consumers process FF prices incidentally, as argued by $\mathrm{H} 3$, then it is not that they have poor memory for prices, it is consistent with the idea that this memory can be better tapped using recognition, leading to a recognition advantage of FFs over Euros.

\subsection{Purchase Intention}

$\mathrm{H} 4$ argued that there would be consequences of whether shoppers over-, under- or accurately recalled prices on purchase intentions, but this effect would be particularly true for unfamiliar price formats. To test $\mathrm{H} 4$, we conducted a 2 (currency: $€ / F F) \times 3$ (estimation error in recall: underestimate, accurate, overestimate) on purchase intentions. This analysis revealed an interaction effect between currency formats and estimation error $(F(2,487)=4.48, p<0.05)$. Means are displayed in Fig. 2.

The pattern of the means reveals that in the FF condition, the type of estimation error has no effect on purchase intentions $(\mathrm{Ms}=4.51,5.00$, and 4.88 for underestimate, accurate, and overestimate, respectively, $F(2,271)=1.85, p=0.16)$. On the other hand, in the Euro condition, intentions are higher when shoppers underestimate price $(\mathrm{M}=5.17)$, as compared to overestimate price $(\mathrm{M}=4.10)$, with intentions being in the middle of these two when price is accurately recalled $(\mathrm{M}=$ $4.85, F(2,216)=4.39, p<0.05)$.

\section{General Discussion}

\subsection{Conclusion}

This paper examined the price knowledge paradox in the context of the Euro introduction. This effect captures the phenomenon that consumers have lower confidence in their price memory for unfamiliar (versus familiar) prices, but, in fact, have better recall of unfamiliar (versus familiar) prices. Building on Monroe and Lee's [15] idea that price memory should be dealt with as a process and not merely a result independent from the price information processing model that is put in place, we propose that consumers process prices expressed in an unfamiliar currency, the Euro, more intentionally than they process prices in a familiar currency, the French Franc. Thus, price memory is better when prices are expressed in an unfamiliar currency, even though this price information is more cognitively complex.

Second, we propose that consumers are differentially aware of how intentionally (more vs. less) they are processing prices. The two together, processing unfamiliar prices intentionally, but being unaware of doing so, leads to consumers having better recall for Euro prices, but lower confidence in their memory of these prices with downstream consequences for 
Fig. 2 Purchase intentions as a function of direction of errors and currency format

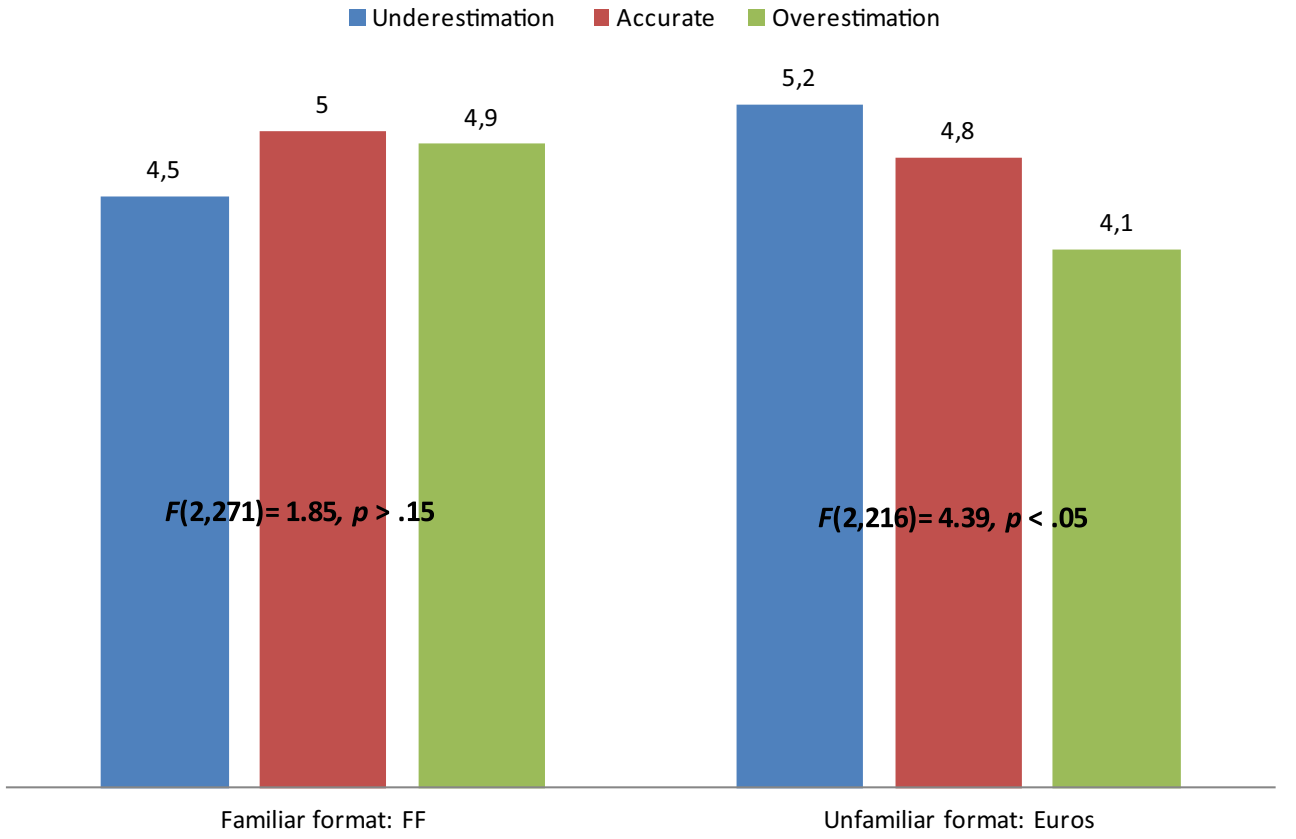

purchase intentions. That is, consumers do not know what they know.

We further propose that whether price is processed more intentionally (i.e., with conscious attention) or less intentionally (i.e., with less conscious attention) has different effects on recall and recognition and introduce the construct of recognition advantage as a way of identifying the manner in which prices are processed. Specifically, whereas recall speaks to a shopper's conscious and intentional attention to price information, recognition can capture if even incidental attention was paid to prices as part of a non-conscious or subconscious process. Recognition is an easier task than recall, leading to the likelihood of accurate recognition being greater than the likelihood of accurate recall. The differential advantage that recognition provides over recall, referred to as the "recognition advantage," is expected to be higher with lower intentional price processing. Price familiarity should affect the extent of attention that consumers pay to prices: the more familiar the price format, the less likely it is to attract intentional attention. Thus, unfamiliar price formats should have lower recognition advantage but higher recall accuracy than familiar price formats, supporting the idea that consumers intentionally process unfamiliar prices.

A field experiment among 683 French shoppers 6 months before the changeover to the Euro showed evidence supporting the contention that shoppers intentionally process price information when prices are expressed in an unfamiliar currency, leading them to better recall exact nominal prices. On the other hand, shoppers that face familiar prices process this price information less intentionally, allowing them to recognize, but not recall prices accurately. Thus, while recall and recognition of prices in FFs are lower than those in Euros,
FFs enjoy a larger recognition advantage over Euros. That is, the difference between the explicit measure of recall tapping higher intentional processing, and recognition that is able to tap lower intentional processing, is greater for FFs. However, consumers are less confident about their ability to recall unfamiliar price information (Euros) as compared to familiar price information (FFs) leading to the price knowledge paradox.

We then go on to examine the effect of currency frame on the direction of recall errors, with their downstream consequences for purchase intentions. Interestingly, while consumers are less likely to have erroneous memory with an unfamiliar currency (€s), when they do, their direction has a significant impact on purchase intention. Thus, when exposed to a new currency, consumers pay more attention to price that, in turn, increases purchase intentions if consumers underestimate prices. Alternatively, while consumers are more likely to make memory errors with FFs, the directions of those errors do not affect purchase intentions. Therefore, buying decisions are differently impacted depending on how intentionally consumers process prices.

Overall, results show that consumers (i) are less confident of their memory for unfamiliar currency formats ( $€$ s), (ii) have more accurate recall and recognition for prices expressed in unfamiliar currency formats (€s) - together leading to the price knowledge paradox. Further, consumers who are unable to recall prices accurately, (iii) are better able to recognize them for familiar currency formats (FFs), and (iv) have higher purchase intentions for a product when they underestimate its price, but only for unfamiliar price formats (€s).

We now discuss the theoretical and managerial contributions of this research. 


\subsection{Theoretical Implications}

Confidence in Price Memory One of the primary contributions of this research is to show that currency format moderates the level of overconfidence that consumers have in their price memory, which has been shown to be around $15 \%$ on average [3]. We found that the level of overconfidence in FF is in the order of $67.95 \%$ (that is $89.63 \%$ reported that they could recall the exact price, but only $21.65 \%$ were able to accurately do so; rows $3 b$ and $4 b$ in Table 1). However, in Euro price formats, the analogous level is only $26.96 \%$ (79.52 less $52.56 \%$ ).

In this paper, we find substantially higher levels of accuracy of recall and recognition for Euro prices, in marked contrast to earlier research. Thus, one of the theoretical contributions of this paper is to demonstrate that the robust effect of poor absolute level of price memory is attenuated when prices are processed intentionally - that is, for unfamiliar price formats.

This paper examined the case of unfamiliar price formats due to the transition to the Euro, but conceptually these results should also generalize to any other situation where prices are intentionally processed. These could include scenarios where prices are unfamiliar, where other contextual factors encourage intentional attention to prices (e.g., expensive products), or where individual differences motivate consumers to attend to price (e.g., lower income or deal-prone consumers).

Linking Memory Outputs to Attention Process This research also adds to the body of evidence that price memory is multidimensional as it depends on the underlying process of price information $[15,21]$. Specifically, we examined the actual memory scores (recall and recognition) to assess which prices were processed intentionally (vs. incidentally), but examined the differential advantage that recognition provided over recall to assess whether prices were processed incidentally (versus not at all). The construct of recognition advantage adds to the literature on the metrics of memory measures. Specifically, we found that shoppers facing familiar prices were able to correctly recognize the actual price without any previous correct price recall, suggesting that they had processed price information, albeit in a less intentional manner. These results highlight the need for research to use multiple measures to examine price memory and understand how prices are processed.

Recall of Complex Inputs This study also adds to prior research that has shown the counterintuitive finding that cognitively more complex inputs are, paradoxically, easier to encode, leading to better recall. Examples of cognitively complex inputs include size-amount congruity [5], and visualverbal or numeric presentation mode [22, 23].

For example, Coulter [5] showed that price presentation format can itself activate either implicit or explicit memory:
Consumers exposed to non-congruent (versus congruent) price information perform better in explicit (versus implicit) memory tasks. When people process numbers and the physical size of the numbers (i.e., font size) at the same time, a large number displayed in a small font (incongruous) can increase recall scores but decrease the likelihood of choice. This is what is termed the size congruity effect.

In a different demonstration of how more cognitively complex price inputs are better recalled, Viswanathan and Childers [23] argued and showed that information written in figures (e.g., " 5 calories") is more cognitively complex than written verbal information (e.g., "low calories") but is better recalled. Consistent with this line of research, Vanhuele, Laurent, and Drèze [22] showed that price recall depends on verbal or visual encoding: the fewer the syllables in a verbal price, or the more unusual the visual price pattern, the better the recall.

\subsection{Managerial Implications}

This research provides managers with important insights that should help pricing decisions. In particular, managers and public authorities facing a monetary changeover like the shift to the Euro or a currency devaluation should be aware that consumers will have better memory for these new prices than they did for the earlier price. These results are also relevant for retailers and manufacturers that target foreign consumers in duty free shops or in tourist areas. Especially, if stores are willing to present their products with local (e.g., US\$) and foreign currencies (e.g., Euros), they should consider that foreign consumers (e.g., European consumers) are more likely to recall and purchase a product with a price advantage displayed in the local and unfamiliar currency (e.g., US\$). This is a counterintuitive managerial implication.

In general, shoppers demonstrate low accuracy in price recall but are still familiar with prices and are most often able to recognize them in a familiar currency format. Conversely, when prices are expressed in an unfamiliar currency, consumers do recall prices as they process price information more intentionally.

Given that surveys of consumers typically state that price is one of the most important factors in their purchase decision, this paper also allows for a reconciliation of the findings regarding poor price recall with the stated importance of prices in a purchase decision. Results show that purchase intentions are affected by the price recall errors committed only when prices are displayed in the unfamiliar currency.

\subsection{Limitations and Areas for Future research}

Future research should examine how robust the results reported are to marketing variables (e.g., product category knowledge, purchase frequency), and individual differences in pricesensitivity (e.g., deal-prone shoppers) that have been shown to 
affect price processing $[8,24]$. Future research could also examine how long it takes for an unfamiliar currency to begin to be processed like a familiar one, and what would happen if countries reverted to an older currency (e.g., Greece and the Euro).

Acknowledgments This research is financially supported by the Spanish Ministry of Education \& Science project quoted SEJ2007-65897. We thank Pierre Desmet and Vicki Morwitz for their comments on an earlier version.

\section{References}

1. Aalto-Setälä V, Raijas A (2003) Consumer price knowledge before and after the euro changeover. Int J Consum Stud 27(3):210-217

2. Aalto-Setälä V, Raijas A (2005) How long does it take to learn prices: the importance of nominal values in the price learning process. J Euro-Mark 15(1):29-37

3. Alba JW, Hutchinson JW (2000) Knowledge calibration: what consumers know and what they think they know. J Consum Res 27(2): $123-156$

4. Amado S, Teközel M, Topsever Y, Ranyard R, Del Missier F, Bonini N (2007) Does "000,000" matter? Psychological effects of Turkish monetary reform. J Econ Psychol 28(2):154-169

5. Coulter K (2003) The effects of congruent/incongruent magnitude representation on explicit and implicit knowledge of prices. J Prod Brand Manag 12(5):293-306

6. Dehaene S (1992) Varieties of numerical abilities. Cognition 44:1-4

7. Dickson PR, Sawyer AG (1990) The price knowledge and search of supermarket shoppers. J Mark 54(3):42-53

8. Gaston-Breton C, Raghubir P (2013) Opposing effects of sociodemographic variables on price knowledge. Mark Lett 24(1): $29-42$
9. Grewal D, Monroe K, Krishnan R (1998) The effects of pricecomparison advertising on buyers' perceptions of acquisition value, transaction value, and behavioral intention. J Mark 62(2):46-59

10. Krishna A, Briesch R, Lehmann DR, Yuan H (2002) A meta-analysis of the impact of price presentation on perceived savings. J Retail 78(2):101-118

11. Le Boutillier J, Shore Le Boutillier S, Neslin S (1994) A replication and extension of the Dickson and Sawyer price-awareness study. Mark Lett 5(1):31-42

12. Marques F, Dehaene S (2004) Developing intuition for prices in euros: rescaling or relearning prices? J Exp Psychol Appl 10:148155

13. Mazumdar T, Monroe K (1990) The effects of buyers' intentions to learn price information on price encoding. J Retail 66(1):15-32

14. Mazumdar T, Raj SP, Sinha I (2005) Reference price research: review and propositions. J Mark 69(4):84-102

15. Monroe K, Lee A (1999) Remembering versus knowing: issues in buyers' processing of price information. J Acad Mark Sci 27(2):207225

16. Mussweiler T, Englich B (2003) Adapting to the euro: evidence from bias reduction. J Econ Psychol 24(3):285-292

17. Poltrock S, Schwartz D (1984) Comparative judgements of multidigit numbers. J Exp Psychol Learn Mem Cogn 10(1):32-45

18. Raghubir P, Srivastava J (2002) Effect of face value on product valuation in foreign currencies. J Consum Res 29(3):335-348

19. Schneider H, Kelemci Schneider G (2006) Consumer price knowledge in Turkey-before and after the changeover of the national currency. J Prod Brand Manag 15(7):450-457

20. Shafir E, Diamond P, Tversky A (1997) Money illusion. Q J Econ 112(2):341-374

21. Vanhuele M, Drèze X (2002) Measuring the price knowledge shoppers bring to the store. J Mark 66(4):72-85

22. Vanhuele M, Laurent G, Drèze X (2006) Consumers' immediate memory for prices. J Consum Res 33(2):163-172

23. Viswanathan M, Childers T (2000) Representation of numerical and verbal product information in consumer memory. J Bus Res 47(2): $109-120$

24. Wakefield K, Inman J (1993) Who are the price vigilantes? an investigation of differentiating characteristics influencing price information processing. J Retail 69(2):216-233 